\title{
AVALIAÇÃO DE CARACTERÍSTICAS ERGONÔMICAS NO POSTO DO OPERADOR EM COLHEDORAS COMBINADAS ${ }^{1}$
}

\author{
GUSTAVO FONTANA ${ }^{2}$, ROUVERSON P. DA SILVA ${ }^{3}$, AFONSO LOPES ${ }^{3}$, \\ CARLOS E. A. FURLANI ${ }^{3}$
}

\begin{abstract}
RESUMO: Com o propósito de fornecer dados para a avaliação de características ergonômicas no posto do operador de quatro colhedoras combinadas presentes na agricultura brasileira, foram realizadas, na região de Uberaba - MG, determinações das distâncias, a partir do ponto de referência do assento até os órgãos de comandos das colhedoras. Dentre as máquinas analisadas, a colhedora NH TC 57 foi a que apresentou melhores características ergonômicas do projeto interno da cabine.
\end{abstract}

PALAVRAS-CHAVE: ergonomia, colhedoras combinadas, SIP.

\section{ERGONOMIC EVALUATION IN THE OPERATOR'S POSITION OF COMBINE HARVESTER}

SUMMARY: The present work was developed in the region of Uberaba - MG, Brazil, with the purpose of supplying data for the evaluation of ergonomics characteristics in the position of the operator of some harvesters. It had been determined the distances from the seat index point until the more used organs of commands in the harvesters. Amongst the analyzed machines, the harvester NH TC 57 was the one that presented better ergonomic characteristics of the internal project of the cabin.

KEYWORDS: ergonomics, combine harvester, SIP.

\section{INTRODUÇÃO}

A colheita é uma das operações mais importantes na agricultura devido ao seu alto valor agregado e da sua boa execução depende o retorno dos investimentos realizados em todo o ciclo produtivo de uma cultura. $\mathrm{O}$ aumento da população e a necessidade de produzir mais alimentos, aliados à redução do número de pessoas empregadas na agricultura, têm conduzido as operações de colheita a uma crescente mecanização (BALASTREIRE, 1987). SILVEIRA (1987) afirma que, na escolha de uma máquina agrícola, não se devem avaliar somente a potência, o consumo, o torque e outros aspectos ligados ao desempenho do equipamento, mas também a segurança de quem vai operála, pois a capacidade operacional do trabalho agrícola depende das condições em que ele é realizado.

A atividade fundamental dos operadores das colhedoras combinadas é realizada no posto de condução na cabine, sendo de grande importância a aplicação de critérios ergonômicos que permitam estabelecer a correta adaptação dos componentes do sistema homem-máquina. Para isso, é preciso considerar as características dos operadores e do trabalho que se realiza, alcançando, desse modo, maior eficiência produtiva, maior grau de conforto e segurança na tarefa e obtendo melhoria das condições de trabalho. SCHLOSSER et al. (2002), avaliando o padrão antropométrico dos operadores de tratores agrícolas da Depressão Central do Rio Grande do Sul, concluíram que existem diferenças

\footnotetext{
${ }^{1}$ Trabalho apresentado no XXXI Congresso Brasileiro de Engenharia Agrícola.

${ }^{2}$ Engoㅗ Agrícola, mestrando em Máquinas Agrícolas, ESALQ/USP, e-mail: agri_fontana@ yahoo.com.br

${ }^{3}$ Prof. Dr., Departamento de Engenharia Rural, FCAV/UNESP, Jaboticabal - SP, Fone: (0XX16) 3209.2637, e-mail: rouverson@fcav.unesp.br

Recebido pelo Conselho Editorial em: 15-10-2002

Aprovado pelo Conselho Editorial em: 1ํ-7-2004
} 
entre esse padrão e os parâmetros utilizados pela indústria, confirmando a hipótese de que os tratores agrícolas atualmente comercializados no Brasil podem não oferecer o conforto necessário aos operadores da região estudada.

A ergonomia é o estudo do relacionamento entre o homem e o trabalho, englobando equipamentos, ambiente e a aplicação dos conhecimentos de anatomia, fisiologia e psicologia na solução dos problemas surgidos desse relacionamento (IIDA, 1997). De acordo com GRANDJEAN (1982), a ergonomia tem como objetivo prático a adaptação do posto de trabalho, instrumentos, máquinas, horários e ambiente às exigências do homem.

Para a realização dos seus objetivos, a ergonomia estuda uma diversidade de fatores que são: o homem e suas características físicas, fisiológicas e psicológicas; as máquinas, mobiliário, equipamentos e instalações; o ambiente, que contempla a temperatura, ruídos, vibrações, luz, cores, etc.; a organização, que constitui todos os elementos citados no sistema produtivo, considerando horários, turnos e equipes, e as consequiências do trabalho nos quais entram as questões relacionadas com os erros e acidentes, além da fadiga e do estresse (IIDA, 1997).

Alguns autores têm desenvolvido trabalhos para estudar a aplicação da ergonomia em máquinas agrícolas. BAEZA \& CASABELLA (1991) desenvolveram um estudo para avaliar a ergonomia da cabine de comando de colhedoras de cana-de-açúcar em Cuba, analisando o ajuste dimensional da mesma às características do operador e vias de acesso à cabine. DUPUIS, citado por MEIRELLES (1976), propôs vários princípios para a disposição dos comandos de um trator agrícola, dentre os quais se destaca a posição do pedal de embreagem, do volante e do acelerador. RIBEIRO (2000) realizou uma avaliação comparativa da ergonomia no posto do operador em três tratores agrícolas de rodas de diferentes potências, concluindo que o trator com potência de 77,3 kW $(105,2 \mathrm{cv})$ foi o que apresentou o projeto ergonômico mais adaptado às normas internacionais.

Este trabalho teve por objetivo analisar quatro modelos de colhedoras combinadas, utilizadas na agricultura brasileira, avaliando suas características ergonômicas no posto do operador para comparálas com as áreas de ótimo e máximo acesso aos comandos, visando ao aperfeiçoamento tecnológico dessas máquinas.

\section{MATERIAL E MÉTODOS}

A análise ergonômica foi realizada em quatro colhedoras combinadas, localizadas em três propriedades produtoras de milho da região de Uberaba - MG. Foram utilizadas neste trabalho as colhedoras New Holland TC-57 e 8040, SLC 6200 e Massey Ferguson 3640, cujas características são mostradas na Tabela 1. As máquinas foram selecionadas de acordo com o perfil da mecanização agrícola regional, determinado por SILVA et al. (1998).

TABELA 1. Características das colhedoras avaliadas.

\begin{tabular}{lcccc}
\hline \multicolumn{1}{c}{ Características } & NH TC -57 & NH-8040 & SLC 6200 & MF 3640 \\
\hline Potência kW - (cv) & $125-(170)$ & $100-(135)$ & $110-(148)$ & $78-(105)$ \\
Número de cilindros & 6 (turbo) & 6 (aspirado) & 6 (turbo) & 6 (turbo) \\
Cabine & Sim & Não & Não & Não \\
Idade (horas) & 1.835 & 3.250 & 3.400 & 1.185 \\
\hline
\end{tabular}

\section{Dispositivo para a simulação do ponto de referência do assento (SIP)}

A avaliação ergonômica das colhedoras foi realizada por meio de medidas a partir do ponto de referência do assento (SIP), que, de acordo com a norma NBR NM-ISO 5353 (ABNT, 1999), "pode ser considerado para fins de projeto do local de trabalho do operador, ser equivalente à intersecção 
do plano vertical central que passa pela linha de centro do assento no eixo de rotação teórico entre o tronco e coxas humanos".

Para a determinação do ponto de referência do assento (SIP), foi construído um dispositivo em madeira de lei (Figura 1), seguindo as orientações da NBR NM-ISO 5353 (ABNT, 1999). Para minimizar o atrito entre o dispositivo e o assento das colhedoras, utilizou-se um tecido de percal e, em seguida, adicionaram-se, progressivamente, massas cilíndricas de 5 e $10 \mathrm{~kg}$ até atingir $65 \mathrm{~kg}$, o que, adicionado à massa do dispositivo, representa a massa $75 \mathrm{~kg}$, considerada como massa média dos operadores brasileiros.

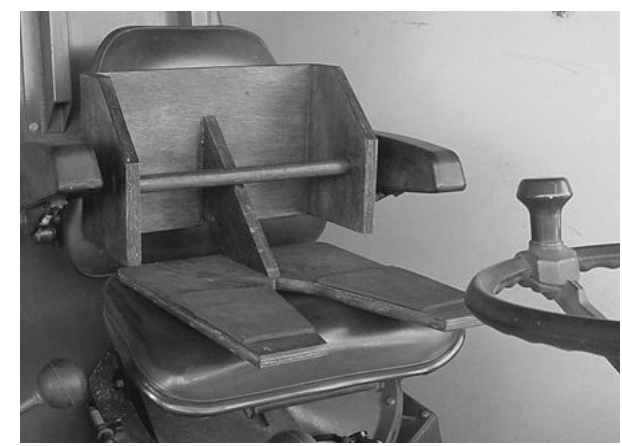

FIGURA 1. Dispositivo para simulação do SIP

\section{Avaliação ergonômica}

Com o auxílio de trenas de aço graduadas em centímetros e de um nível, as distâncias do SIP até os órgãos de comando foram medidas em três dimensões ( $x, y$ e $z$ ) e colocadas em um gráfico contendo as áreas de máximo e ótimo acesso aos comandos, com o objetivo de obter melhor visualização dos resultados (Figura 2).

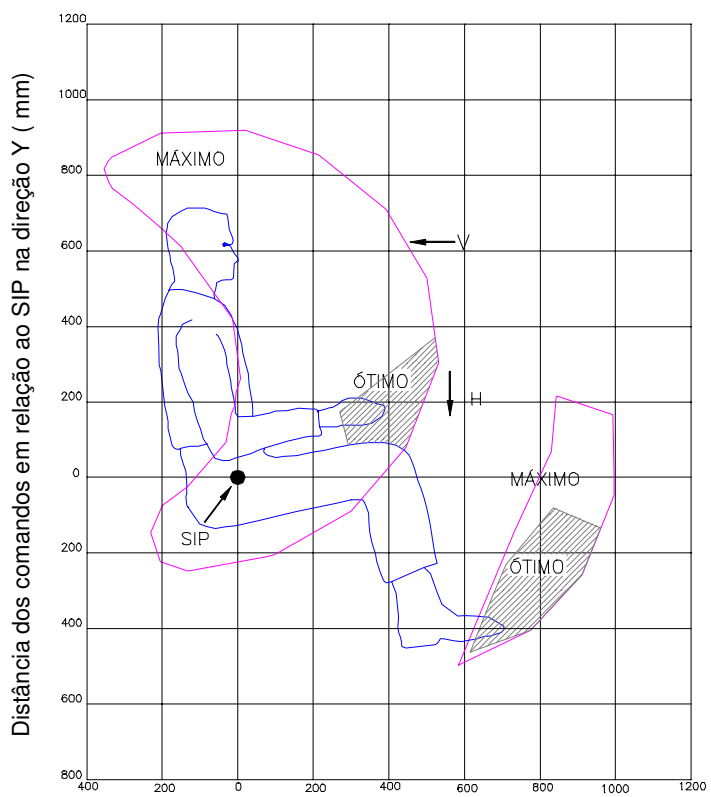

Distância dos comandos em relação ao SIP na direção $X(\mathrm{~mm})$

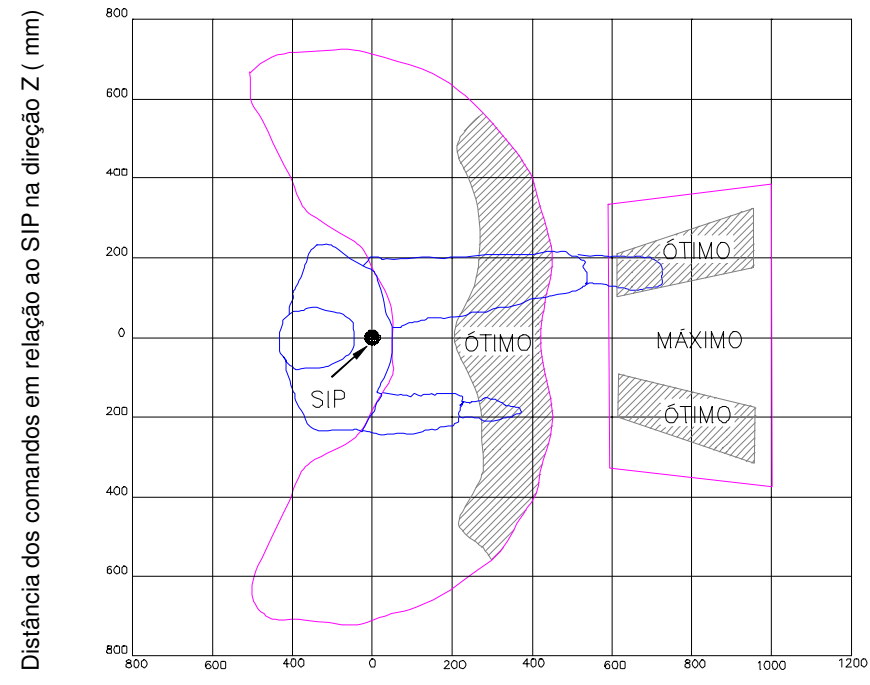

Distância dos comandos em relação ao SIP na direção $X(\mathrm{~mm})$

FIGURA 2. Áreas de máximo e ótimo de acesso aos órgãos de comando, nas três dimensões (McCORMICK, 1970, citado por RIBEIRO, 2000). 
Além da avaliação ergonômica, aplicou-se um questionário para conhecer a opinião dos operadores sobre o acesso à colhedora, regime de trabalho e a facilidade de execução dos comandos, dentre outros fatores (Figura 3). Nesse questionário, os operadores atribuíram valores de 1 a 5 , em ordem decrescente de avaliação, em que o maior valor indica uma avaliação ótima e o menor valor um pior resultado. Para os resultados obtidos, foram calculadas as médias dos valores atribuídos pelos operadores a cada item e para cada colhedora. O objetivo desse questionário foi confrontar as regiões de ótimo acesso determinadas na avaliação ergonômica, com a opinião dos operadores.

\begin{tabular}{|c|c|c|c|c|c|}
\hline \multicolumn{6}{|l|}{$\begin{array}{l}\text { COLHEDORA: } \\
\text { OPERADOR: }\end{array}$} \\
\hline \multirow[t]{2}{*}{ Horas trabalhadas: } & \multicolumn{5}{|c|}{ Notas } \\
\hline & 1 & 2 & 3 & 4 & 5 \\
\hline \multicolumn{6}{|l|}{ Acesso à colhedora } \\
\hline \multicolumn{6}{|l|}{ Conforto do assento } \\
\hline \multicolumn{6}{|l|}{ Acesso ao acelerador manual } \\
\hline \multicolumn{6}{|l|}{ Acesso à alavanca da plataforma } \\
\hline \multicolumn{6}{|c|}{ Acesso à alavanca do descarregador } \\
\hline \multicolumn{6}{|l|}{ Acesso à alavanca do câmbio } \\
\hline \multicolumn{6}{|l|}{ Acesso à embreagem } \\
\hline \multicolumn{6}{|l|}{ Acesso aos pedais de freio } \\
\hline \multicolumn{6}{|l|}{ Acesso ao volante } \\
\hline Visibilidade dos instrumentos & & & & & \\
\hline
\end{tabular}

FIGURA 3. Modelo da ficha para avaliação pelos operadores do acesso aos órgãos de comando da colhedora.

Os resultados obtidos com as avaliações ergonômicas foram comparados entre si, visando a gerar subsídios para pesquisas futuras que busquem o aperfeiçoamento tecnológico do maquinário agrícola nacional, priorizando a ergonomia como parte integrante dessa tecnologia.

\section{RESULTADOS E DISCUSSÃO}

\section{Colhedora NH TC-57}

Para a colhedora NH TC-57, observa-se que, em relação às coordenadas x e z, dos 36 comandos existentes, oito estão fora da região de máximo acesso, enquanto $66,7 \%$ se encontram na região de ótimo e de máximo acesso. Com relação às coordenadas x e y, encontram-se na região de ótimo e de máximo acesso três e vinte um comandos, respectivamente, totalizando 77,8\% do total (Figura 4). Os comandos que se encontram na região de ótimo acesso em relação às coordenadas x e z (Figura 4), são comandos importantes como a alavanca de velocidade de deslocamento e o pedal de embreagem. Por outro lado, os comandos que estão fora da área de máximo acesso, são comandos menos utilizados durante uma jornada de trabalho.

Para as coordenadas x e y, os comandos que se encontram na região de ótimo acesso, não são tão importantes, pois são regulados apenas uma única vez durante a jornada. Apesar da quantidade de comandos fora da região de máximo acesso, há que se considerar que boa parte deles são acionados apenas no início de cada colheita. Assim, o esforço do operador é realizado poucas vezes durante a jornada. 


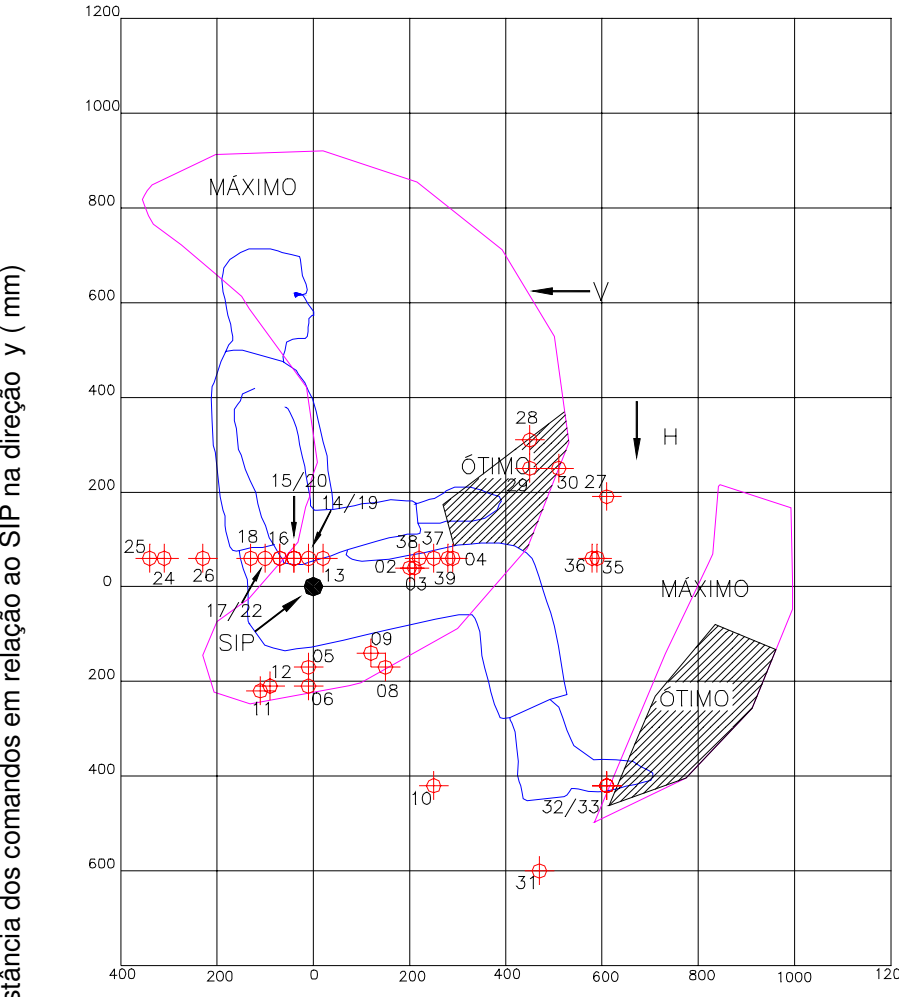

Distância dos comandos em relação ao SIP na direção $\times(\mathrm{mm})$

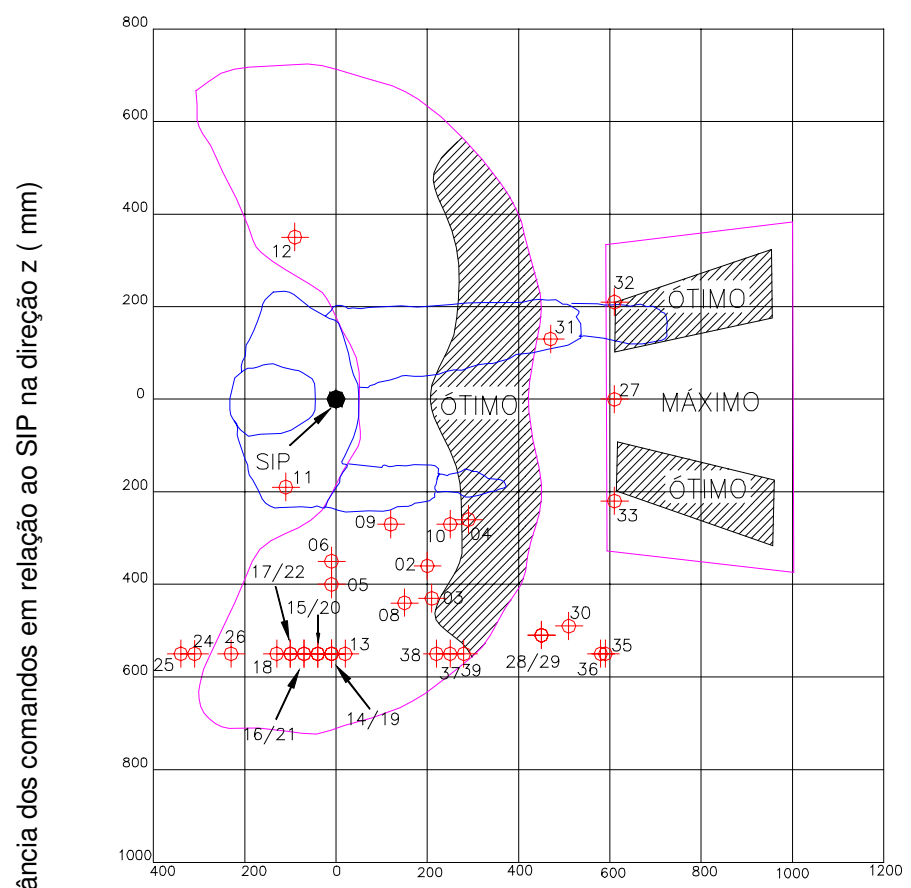

Distância dos comandos em relação ao SIP na direção x ( $\mathrm{mm})$

\begin{tabular}{|c|c|}
\hline 2 & Alavanca da altura da plataforma de corte \\
\hline 3 & Alavanca da altura do molinete \\
\hline 4 & Alavanca da velocidade de deslocamento \\
\hline 5 & Alavanca de flutuação \\
\hline 6 & Alavanca do acelerador \\
\hline 8 & Alavanca do câmbio \\
\hline 9 & Alavanca do côncavo \\
\hline 10 & Alavanca do côncavo \\
\hline 11 & Alavanca do freio de estacionamento \\
\hline 12 & Alavanca do tubo de descarga de grãos \\
\hline 13 & $\begin{array}{l}\text { Botão de acionamento da descarga de } \\
\text { grãos }\end{array}$ \\
\hline 14 & $\begin{array}{l}\text { Botão de acionamento da lâmpada de } \\
\text { aviso para tráfego }\end{array}$ \\
\hline 15 & Botão de acionamento da plataforma \\
\hline 16 & $\begin{array}{l}\text { Botão de acionamento das lanternas e } \\
\text { faróis }\end{array}$ \\
\hline 17 & $\begin{array}{l}\text { Botão de acionamento do dispositivo de } \\
\text { segurança do motor }\end{array}$ \\
\hline 18 & $\begin{array}{l}\text { Botão de acionamento do ajuste horizontal } \\
\text { do molinete }\end{array}$ \\
\hline 19 & Botão de acionamento do reversor \\
\hline 20 & $\begin{array}{l}\text { Botão de acionamento do sistema "self } \\
\text { levelling" das peneiras }\end{array}$ \\
\hline 21 & Botão de acionamento do sistema industrial \\
\hline 22 & Botão de acionamento faróis de trabalho \\
\hline 24 & Botão de partida \\
\hline 25 & CAAP + flutuação lateral \\
\hline 26 & Chave de partida \\
\hline 27 & Coluna de direção \\
\hline 28 & Interruptor do sensor de perdas \\
\hline 29 & $\begin{array}{l}\text { Manípulo variador da sensibilidade do } \\
\text { sensor das peneiras }\end{array}$ \\
\hline 30 & $\begin{array}{l}\text { Manípulo variador da sensibilidade do } \\
\text { sensor do saca-palhas }\end{array}$ \\
\hline 31 & Pedal de ajuste da coluna de direção \\
\hline 32 & Pedal de embreagem \\
\hline 33 & Pedal do freio direito \\
\hline 35 & Pisca-alerta \\
\hline 36 & Seletor de indicação do tacômetro \\
\hline 37 & Variador do cilindro \\
\hline 38 & Variador do molinete \\
\hline 39 & Variador do ventilador \\
\hline
\end{tabular}

FIGURA 4. Localização dos órgãos de comandos da colhedora NH TC-57, nas três dimensões. 


\section{Colhedora NH 8040}

Para a colhedora NH 8040, observa-se que, em relação às coordenadas x e z, apenas três dos vinte e sete comandos estão fora da região de máximo acesso e 88,9\% encontram-se na região de ótimo e máximo acesso. Observando-se o plano x-y, constata-se que 66,7\% dos comandos se encontram dentro da região de ótimo e máximo acesso, e nove comandos estão fora da região de máximo acesso, exigindo um esforço ergonométrico adicional para que o operador consiga manipulálos (Figura 5). Em relação a esse plano, observa-se que existem comandos localizados fora da área de máximo acesso e que são utilizados principalmente durante a descarga do tanque graneleiro, estando, portanto, posicionados em uma região ruim para o operador, o que dificulta a descarga de grãos com a colhedora em movimento.

Os comandos que se encontram na região de ótimo acesso no plano $\mathrm{x}-\mathrm{z}$, assim como os que se encontram fora da área de máximo, são comandos bastante utilizados na operação de colheita (Figura 6). $\mathrm{Na}$ área de ótimo acesso, encontram-se as alavancas de velocidade de deslocamento, do côncavo e do acelerador, enquanto fora da área de máximo acesso estão as alavancas da altura da plataforma de corte, da altura do molinete e do tubo de descarga de grãos. Entretanto, 88,9\% dos comandos dessa colhedora estão em áreas adequadas para o acesso do operador, classificadas como área de ótimo e máximo acesso.

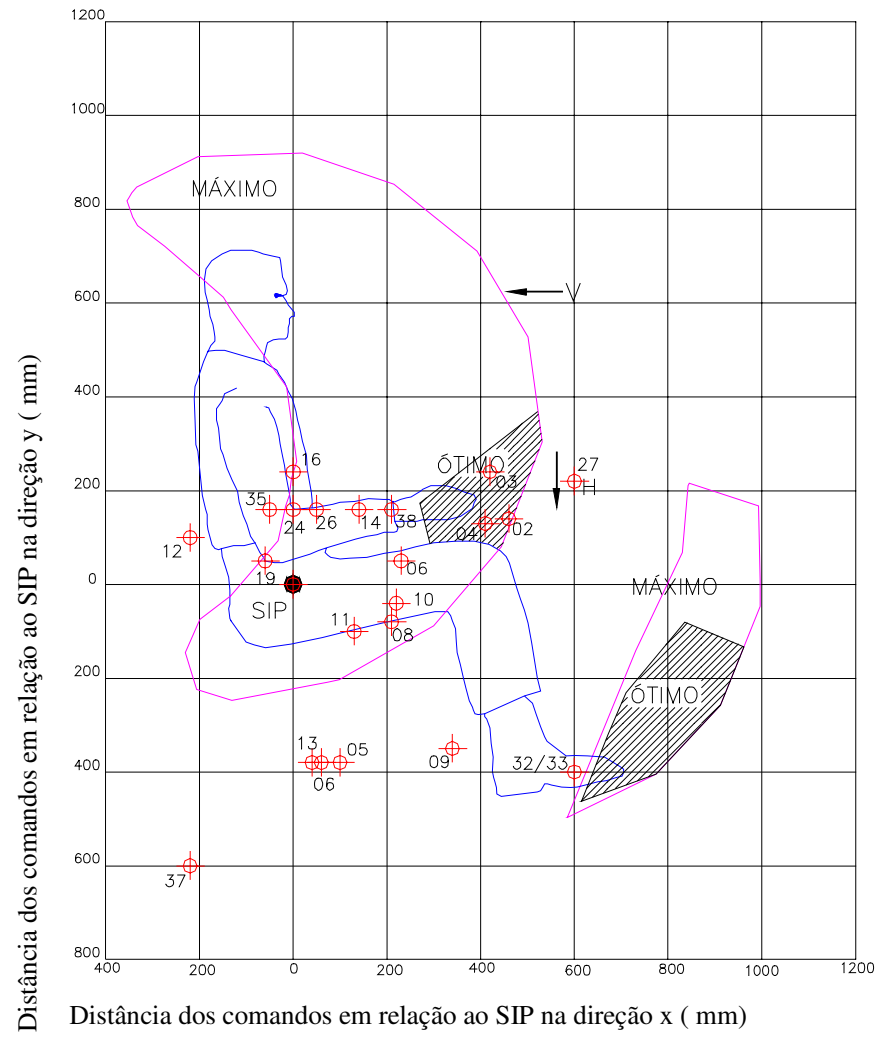

\begin{tabular}{|l|l|}
\hline 2 & Alavanca da altura da plataforma de corte \\
\hline 3 & Alavanca da altura do molinete \\
\hline 4 & Alavanca de velocidade de deslocamento \\
\hline 5 & $\begin{array}{l}\text { Alavanca de acionamento da transmissão da } \\
\text { plataforma de corte }\end{array}$ \\
\hline 6 & $\begin{array}{l}\text { Alavanca de acionamento da transmissão da } \\
\text { trilha }\end{array}$ \\
\hline 7 & Alavanca do acelerador \\
\hline 8 & Alavanca do câmbio \\
\hline 9 & Alavanca do côncavo \\
\hline 10 & Alavanca do côncavo \\
\hline 11 & $\begin{array}{l}\text { Alavanca de acionamento do freio de } \\
\text { estacionamento }\end{array}$ \\
\hline 12 & Alavanca do tubo de descarga dos grãos \\
\hline 13 & Alavanca de acionamento da descarga de grãos \\
\hline 14 & Buzina \\
\hline 16 & Interruptor de luzes \\
\hline 19 & Parada do motor \\
\hline 24 & Botão de partida \\
\hline 26 & Chave de partida \\
\hline 27 & Coluna de direção \\
\hline 28 & Interruptor do sensor de perdas \\
\hline 32 & Pedal de embreagem \\
\hline 33 & Pedal do freio direito \\
\hline 35 & Pisca-alerta \\
\hline 37 & Variador do cilindro \\
\hline 38 & Variador do molinete \\
\hline
\end{tabular}

FIGURA 5. Localização dos órgãos de comandos da colhedora NH 8040, no plano x-y. 


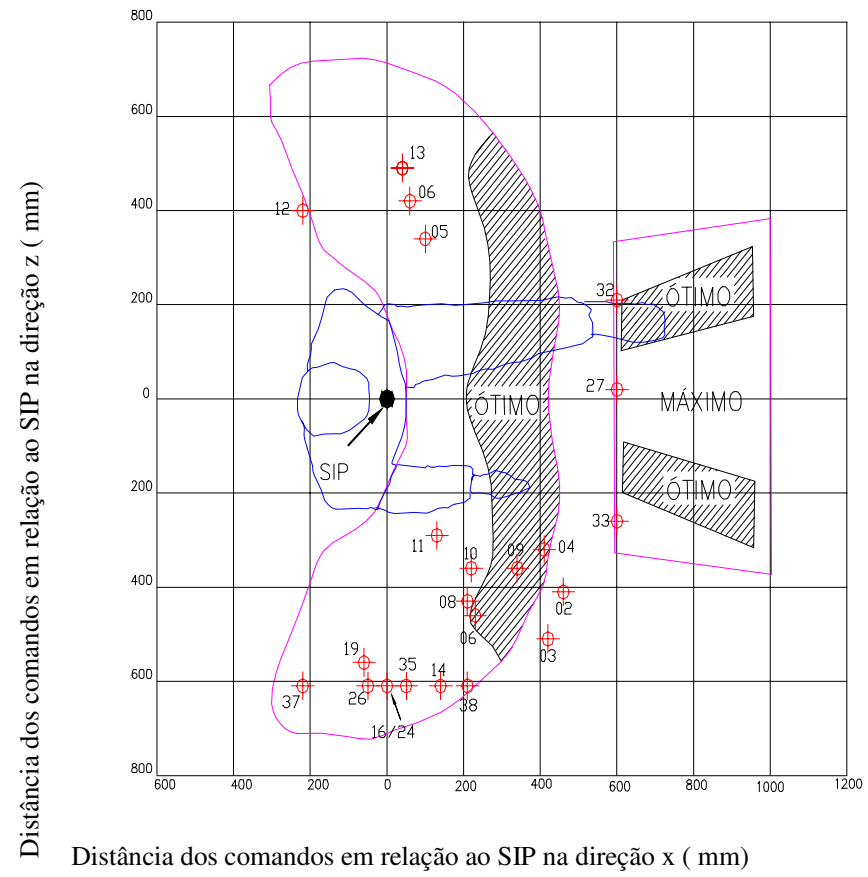

\begin{tabular}{|l|l|}
\hline 2 & Alavanca da altura da plataforma de corte \\
\hline 3 & Alavanca da altura do molinete \\
4 & Alavanca de velocidade da colhedora \\
\hline 5 & $\begin{array}{l}\text { Alavanca de acionamento da transmissão da } \\
\text { plataforma de corte }\end{array}$ \\
\hline 6 & Alavanca de acionamento da transmissão da trilha \\
\hline 7 & Alavanca do acelerador \\
\hline 8 & Alavanca do câmbio \\
\hline 9 & Alavanca do côncavo \\
\hline 10 & Alavanca do côncavo \\
\hline 11 & Alavanca de acionamento do freio de \\
& estacionamento \\
\hline 12 & Alavanca do tubo de descarga dos grãos \\
\hline 13 & Alavanca de acionamento da descarga de grãos \\
\hline 16 & Chave do farol \\
\hline 26 & Chave de partida \\
\hline 27 & Coluna de direção \\
\hline 31 & Pedal de bloqueio da coluna de direção \\
\hline 32 & Pedal de embreagem \\
\hline 33 & Pedal de freio \\
\hline 37 & Variador do cilindro \\
\hline 38 & Variador do molinete \\
\hline 42 & Buzina \\
\hline 44 & Parada do motor \\
\hline & \\
\hline
\end{tabular}

FIGURA 6. Localização dos órgãos de comandos da colhedora NH 8040, no plano x-z.

\section{Colhedora SLC-6200}

Dentre os 22 comandos da colhedora SLC-6200, 63,6\% dos comandos localizados no plano X-Z encontram-se nas regiões de ótimo e máximo acesso (Figura 7). Com relação ao plano x-y, 50\% dos comandos encontram-se na região de máximo e ótimo acesso e $50 \%$ estão fora da região de máximo acesso (Figura 8). Dos comandos localizados na região fora da área de máximo acesso, tanto no plano $\mathrm{x}-\mathrm{y}$ quanto no plano $\mathrm{x}-\mathrm{z}$, cinco podem ser considerados mais utilizados: o variador do cilindro, as alavancas do tubo de descarga dos grãos e do acelerador e os pedais de freio e embreagem.

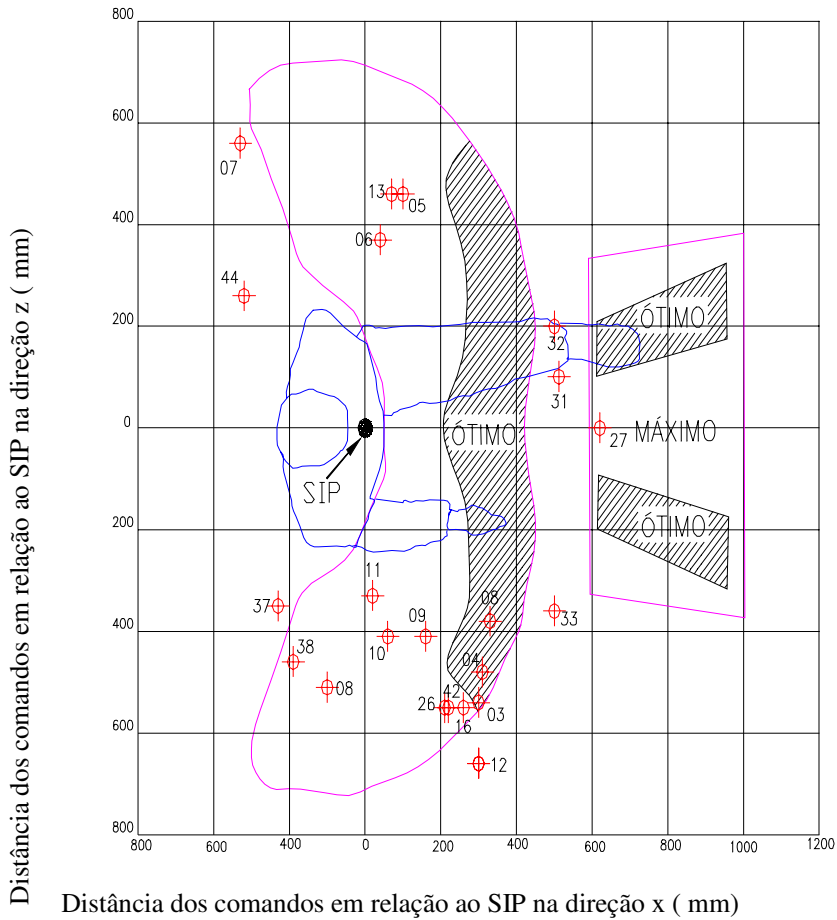

\begin{tabular}{l|l|}
\hline 2 & Alavanca da altura da plataforma de corte \\
\hline 5 & $\begin{array}{l}\text { Alavanca de acionamento da transmissão da } \\
\text { plataforma de corte }\end{array}$ \\
\hline 6 & Alavanca de acionamento da transmissão da trilha \\
\hline 7 & Alavanca do acelerador \\
\hline 8 & Alavanca do câmbio \\
\hline 9 & Alavanca do côncavo \\
\hline 10 & Alavanca do côncavo \\
\hline 11 & $\begin{array}{l}\text { Alavanca de acionamento do freio de } \\
\text { estacionamento }\end{array}$ \\
\hline 12 & Alavanca do tubo de descarga dos grãos \\
\hline 13 & Alavanca de acionamento da descarga de grãos \\
\hline 16 & Chave do farol \\
\hline 26 & Chave de partida \\
\hline 27 & Coluna de direção \\
\hline 31 & Pedal de bloqueio da coluna de direção \\
\hline 32 & Pedal de embreagem \\
\hline 33 & Pedal de freio \\
\hline 38 & Variador do cilindro \\
\hline 42 & Variador do molinete \\
\hline 44 & Buzina \\
\hline
\end{tabular}

FIGURA 7. Localização dos órgãos de comandos da colhedora SLC-6200, no plano x-z. 


\section{Colhedora MF-3640}

Analisando-se a colhedora MF-3640 em relação ao posicionamento dos comandos no plano x-z, observa-se que, dos 20 comandos, apenas $20 \%$ estão fora da região de máximo acesso, enquanto $80 \%$ situam-se nas regiões de ótimo e máximo acesso. Com relação às coordenadas x e y, não se encontram comandos na região de ótimo acesso e $35 \%$ e $65 \%$ estão fora e dentro, respectivamente, da região de máximo acesso (Figura 9).

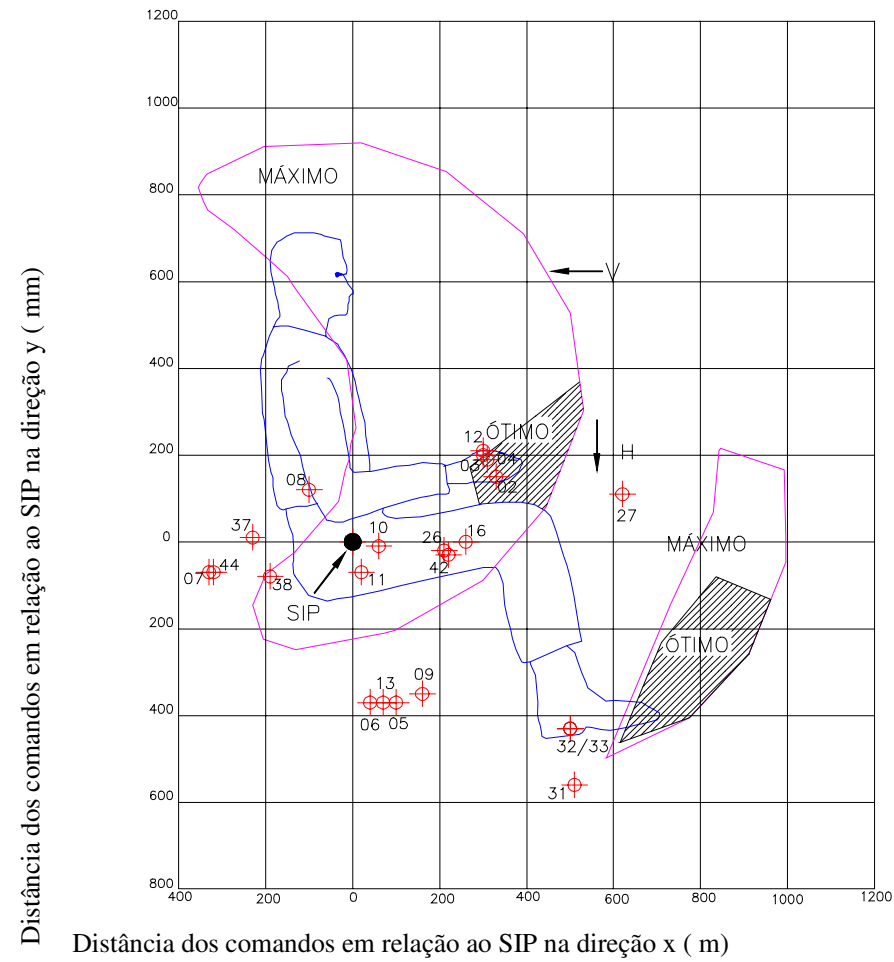

\begin{tabular}{|l|l|}
\hline 2 & Alavanca da altura da plataforma de corte \\
\hline 3 & Alavanca da altura do molinete \\
\hline 4 & Alavanca de velocidade da colhedora \\
\hline 5 & $\begin{array}{l}\text { Alavanca de acionamento da transmissão da } \\
\text { plataforma de corte }\end{array}$ \\
\hline 6 & Alavanca de acionamento da transmissão da trilha \\
\hline 7 & Alavanca do acelerador \\
\hline 8 & Alavanca do câmbio \\
\hline 9 & Alavanca do côncavo \\
\hline 10 & Alavanca do côncavo \\
\hline 11 & $\begin{array}{l}\text { Alavanca de acionamento do freio de } \\
\text { estacionamento }\end{array}$ \\
\hline 12 & Alavanca do tubo de descarga dos grãos \\
\hline 13 & Alavanca de acionamento da descarga de grãos \\
\hline 16 & Chave do farol \\
\hline 26 & Chave de partida \\
\hline 27 & Coluna de direção \\
\hline 31 & Pedal de bloqueio da coluna de direção \\
\hline 32 & Pedal de embreagem \\
\hline 33 & Pedal de freio \\
\hline 37 & Variador do cilindro \\
\hline 38 & Variador do molinete \\
\hline 42 & Buzina \\
\hline 44 & Parada do motor \\
\hline & \\
\hline
\end{tabular}

FIGURA 8. Localização dos órgãos de comandos da colhedora SLC-6200, no plano x-y.

Com relação ao plano x-z, os comandos que estão fora da área de máximo acesso, são reguláveis antes do início da jornada de trabalho da colhedora e, embora não representem grande desconforto para o operador durante a operação, encontram-se ergonomicamente mal localizados (Figura 10).

Em relação às coordenadas $\mathrm{x}$ e $\mathrm{y}$, os comandos mais utilizados estão posicionados dentro da área de máximo acesso, porém muitos outros comandos deveriam estar localizados dentro da área de ótimo acesso, tais como: alavanca de deslocamento de velocidade, alavanca de acionamento da descarga de grãos e a alavanca do tubo de descarga de grãos, que são os comandos mais utilizados durante o trabalho de colheita. 


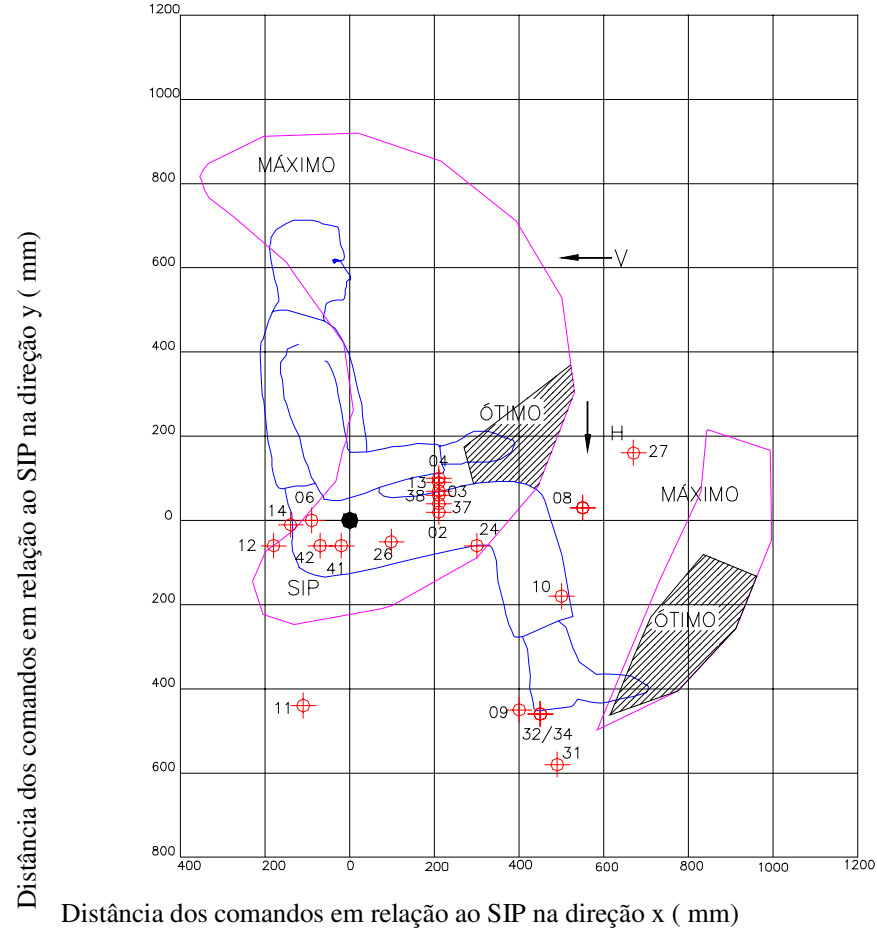

\begin{tabular}{|l|l|}
\hline 2 & Alavanca da altura da plataforma de corte \\
\hline 3 & Alavanca da altura do molinete \\
\hline 4 & Alavanca da velocidade de deslocamento \\
\hline 7 & Alavanca do acelerador \\
\hline 8 & Alavanca do câmbio \\
\hline 9 & Alavanca do côncavo máximo \\
\hline 10 & Alavanca do côncavo mínimo \\
\hline 11 & Alavanca do freio de estacionamento \\
\hline 12 & Alavanca do tubo de descarga dos grãos \\
\hline 13 & Alavanca de acionamento de descarga dos grãos \\
\hline 24 & Botão de partida \\
\hline 26 & Chave de partida \\
\hline 27 & Coluna de direção \\
\hline 31 & Pedal de ajuste da coluna de direção \\
\hline 32 & Pedal de embreagem \\
\hline 33 & Pedal de freio \\
\hline 37 & Variador do cilindro \\
\hline 38 & Variador do molinete \\
\hline 41 & Botão do aquecedor do motor \\
\hline 42 & Botão de acionamento da buzina \\
\hline
\end{tabular}

FIGURA 9. Localização dos órgãos de comandos da colhedora MF-3640, no plano x-y.

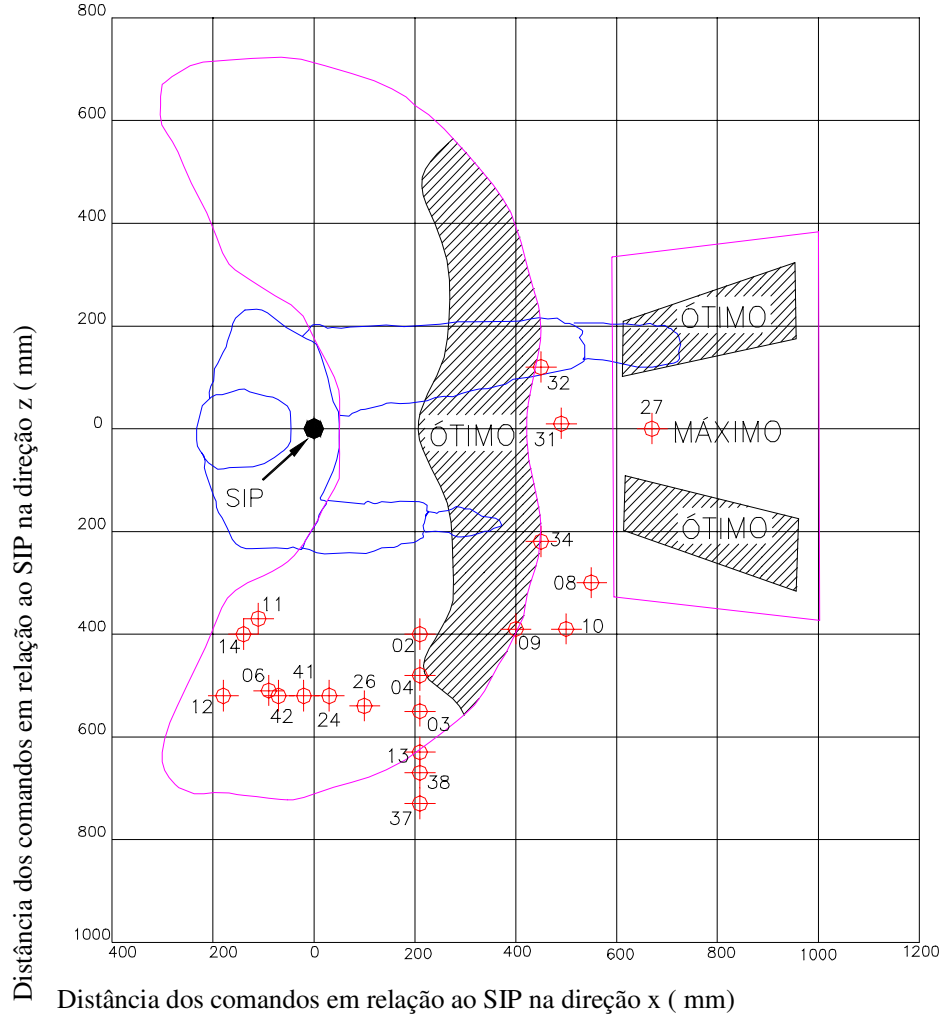

\begin{tabular}{|l|l|}
\hline 2 & Alavanca da altura da plataforma de corte \\
\hline 3 & Alavanca da altura do molinete \\
\hline 4 & Alavanca da velocidade de deslocamento \\
\hline 7 & Alavanca do acelerador \\
\hline 8 & Alavanca do câmbio \\
\hline 9 & Alavanca do côncavo máximo \\
\hline 10 & Alavanca do côncavo mínimo \\
\hline 11 & Alavanca do freio de estacionamento \\
\hline 12 & Alavanca do tubo de descarga dos grãos \\
\hline 13 & Alavanca de acionamento de descarga dos grãos \\
\hline 24 & Botão de partida \\
\hline 26 & Chave de partida \\
\hline 27 & Coluna de direção \\
\hline 31 & Pedal de ajuste da coluna de direção \\
\hline 32 & Pedal de embreagem \\
\hline 33 & Pedal de freio \\
\hline 37 & Variador do cilindro \\
\hline 38 & Variador do molinete \\
\hline 41 & Botão do aquecedor do motor \\
\hline 42 & Botão de acionamento da buzina \\
\hline
\end{tabular}

FIGURA 10. Localização dos órgãos de comandos da colhedora MF-3640, no plano X-Z. 


\section{Avaliação geral da distância dos comandos ao SIP}

Observando-se as avaliações ergonômicas, nota-se que, no plano x-z, a colhedora NH 8040 apresentou 88,9\% dos seus comandos em regiões de ótimo e máximo acesso, caracterizando-a como a colhedora com melhor resultado ergonômico, seguida das colhedoras MF 3640, NH TC 57 e SLC 6200 , com 80,0; 77,8 e 63,5\%, respectivamente. No plano x-y, o melhor resultado foi observado para as colhedoras NH TC 57 e NH 8040, com 66,7\% dos comandos localizados em áreas de ótimo e máximo acesso, seguidas das colhedoras MF 3640 e SLC 6200, com 65,0 e 50,0\%, respectivamente. Por outro lado, quando se analisam apenas os comandos comuns às colhedoras avaliadas, em dimensão espacial (x-y-z), verifica-se que a colhedora NH TC 57 apresenta 100\% desses comandos em áreas de máximo e ótimo acesso, enquanto as demais colhedoras apresentam 87,5\% dos comandos nessas áreas. Essa análise faz-se necessária pelo fato de a colhedora NH TC 57 apresentar alguns comandos específicos provenientes do avanço tecnológico das máquinas agrícolas, tais como os sensores de perdas e peneiras e o controle automático de altura da plataforma.

Comparando-se os resultados da Tabela 2 com a avaliação em dimensão espacial, constata-se a coincidência da opinião dos operadores com relação ao acesso aos órgãos de comando e o estudo ergonômico do projeto interno das cabines das máquinas avaliadas, apontando a colhedora NH TC 57 com a melhor avaliação, seguida das demais colhedoras em estudo.

TABELA 2. Médias das notas atribuídas pelos operadores para o acesso aos órgãos de comando.

\begin{tabular}{lcccc}
\hline \multicolumn{1}{c}{ Itens Observados } & NH TC-57 & NH 8040 & SLC-6200 & MF-3640 \\
\hline Acesso à máquina & 3 & 3 & 4 & 3 \\
Conforto do assento & 5 & 4 & 3 & 4 \\
Acesso ao acelerador manual & 5 & 4 & 5 & 5 \\
Acesso à alavanca da plataforma & 5 & 5 & 5 & 5 \\
Acesso à alavanca do descarregador & 5 & 5 & 5 & 4 \\
Acesso à alavanca do câmbio & 5 & 5 & 5 & 5 \\
Acesso à embreagem & 5 & 5 & 5 & 5 \\
Acesso aos pedais de freio & 5 & 5 & 4 & 5 \\
Acesso ao volante & 5 & 5 & 4 & 5 \\
Visibilidade dos instrumentos & 5 & 3 & 4 & 3 \\
\hline Média & 4,8 & 4,4 & 4,4 & 4,4 \\
\hline
\end{tabular}

\section{CONCLUSÕES}

Pode-se concluir que as colhedoras NH TC-57 e NH 8040 apresentaram o maior número de comandos dentro da área de ótimo e máximo acesso no plano x-y. Com relação ao plano x-z, a colhedora NH 8040 apresentou maior porcentagem de comandos na região de ótimo e máximo acesso.

Na avaliação espacial, a colhedora NH TC 57 apresentou o maior número de comandos dentro da área de ótimo e máximo acesso, sendo também a melhor avaliada pelos operadores.

\section{REFERÊNCIAS}

ASSOCIAÇÃO BRASILEIRA DE NORMAS TÉCNICAS. Máquinas rodoviárias, tratores e máquinas agrícolas e florestais: ponto de referência do assento. NBR NM-ISO 5353. Rio de Janeiro, 1999. 5 p.

BAESA, A.B.; CASABELLA, E.P. Avaliação ergonômica de uma cabine para colhedora de cana-deaçúcar. Revista Brasileira de Saúde Ocupacional, São Paulo, v.19, n.72, p.59-64, 1991.

BALASTREIRE, L.A. Máquinas agrícolas. In: . São Paulo: Manole, 1987. p.269-307. 
GRANDJEAN. E. Fitting the task to the man - an ergonomic approach.. London: Taylor \& Francis, 1982. 379 p.

IIDA, I. Ergonomia: projeto e produção. São Paulo: Edgar Blücher, 1997. 468 p.

MEIRELLES, C.E. Tratores agrícolas. Revista Brasileira de Saúde Ocupacional, São Paulo, v.4, n.14, p.71-80, 1976.

RIBEIRO, M.P. Avaliação ergonômica de tratores com potência de 55,2; 77,3 e 110 kW. 2000.49 f. Monografia (Trabalho de Graduação) - Faculdade de Ciências Agrárias e Veterinárias, Universidade Estadual Paulista, Jaboticabal, 2000.

SCHLOSSER, J.F.; DEBIASI, H.; PARCIANELLO, G.; RAMBO, L. Antropometira aplicada aos operadores de tratores agrícolas. Ciência Rural, Santa Maria, v.32, n.9, p.983-8, 2002.

SILVA, R.P.; PASCHOAL, M.A.; SERON , E.; CAIXETA, R.V. Determinação do índice de mecanização agrícola de Uberaba - MG. In: CONGRESSO BRASILEIRO DE ENGENHARIA AGRÍCOLA, 27., 1998, Poços de Caldas. Anais... Lavras: Sociedade Brasileira de Engenharia Agrícola, 1998.

SILVEIRA, G.M. Tratores gigantes, a tendência atual. A Granja, Porto Alegre, v.1, n.10, p.48-53, 1978.

TEWARK, V.K. ; DATTA, R.K. Development of a wetland seeder from mechanical and ergonomical considerations. Agricultura Mechanization in Asia, Africa and Latin America, Tokyo, v.14, n.3, p.217, 1983. 